\title{
Cross-sectional Assesses on Irrational Use of Veterinary Drugs in Adami Tulu Jiddo Kombolcha Distrct, East Shoa Zone, Oromia Regional State, Ethiopia
}

\author{
Feyyisa Koji ${ }^{1}$, Adem Kumbe ${ }^{2,}$, , Ayele Beyene ${ }^{3}$ \\ ${ }^{1}$ College of Agriculture and Veterinary Medicine, Jimma University, Jimma, Ethiopia \\ ${ }^{2}$ Oromia Agriculture Research Institute, Yabello Pastoral and Dry-land Agricultural Research Center, Yabello, Ethiopia \\ ${ }^{3}$ School of Veterinary Medicine, Hawasa University, Hawasa, Ethiopia \\ Email address: \\ ademkumbe7@gmail.com (A. Kumbe) \\ ${ }^{*}$ Corresponding author
}

To cite this article:

Feyyisa Koji, Adem Kumbe, Ayele Beyene. Cross-sectional Assesses on Irrational Use of Veterinary Drugs in Adami Tulu Jiddo Kombolcha Distrct, East Shoa Zone, Oromia Regional State, Ethiopia. International Journal of Biomedical Science and Engineering.

Vol. 8, No. 3, 2020, pp. 22-27. doi: 10.11648/j.ijbse.20200803.11

Received: August 7, 2020; Accepted: August 19, 2020; Published: September 16, 2020

\begin{abstract}
A cross-sectional study was conducted from November 2014 to March, 2015 at Adami-Tulu Jiddo kombolcha district in five peasant association and four towns to assess the irrational use of veterinary drugs in food producing animals and assess the factors those leads to irrational uses of veterinary drugs from farmers, veterinary clinicians and private veterinary pharmacists' side. Out of 60 farmers interviewed, 55 (91.7\%) of them uses veterinary drugs. From these 55 respondents, 44 $(80 \%)$ of them treat their animals by presenting to the clinic and $11(20 \%)$ of them treat by themselves at home with veterinary drugs. There was statistically significant association $(\mathrm{P}<0.05)$ between source of a drug and response of the disease to treatment. Of the total 60 farmers, $18(30 \%)$ uses black market, $22(36.7 \%)$ uses veterinary pharmacy and $20(33.3 \%)$ uses veterinary clinic as a source of drugs. Among these $17(94.4 \%), 2(9.1 \%)$ and $3(15 \%)$ of them responded as these sources of drugs have no response to treatment from the black market, veterinary pharmacy and veterinary clinic respectively. Regarding with drug regulation problem $7(70 \%)$ of the farmers responded as there were lack of veterinary drug supply and lack of veterinary supervision. In line with clinicians, of the total 10 interviewed, $2(20 \%)$ of them responded as the farmers reject their advice on animals' treatment approach and $10 \%$ of the clinicians depend on the farmers' needs on the way they use the drugs. In line with drug availability and its effectivity related issues, $8(80 \%)$ of clinicians responded as there was no sufficient drug availability and no effective drug for the specific disease. On the other hand from 10 private veterinary pharmacists interviewed, $7(70 \%)$ of them sell drugs without prescription. Generally irrational use of veterinary drugs is a common problem in developing countries where resource and educated human power are not access as wanted. Hence, growing awareness in the community about the rational use of veterinary drugs and controlling the illegal contraband of it were recommended as the main measures to alleviate the expansion of irrational use of vet drugs.
\end{abstract}

Keywords: Adami Tulu, Veterinary Drug, Irrational Use, Rational Use, Factors for Irrational Use

\section{Introduction}

Drugs, in animals can be used for various purposes; such as therapeutic, prophylactic [5], growth promotion and other uses [6]. When veterinary drugs are indicated rationally in right dose and route of administration, the potential damages of their use are reduced and their efficacy increased. Rational use of drugs in veterinary medicine has both economic and public health significances [3].

Medicine use is rational (appropriate, proper, correct) if patients receive the appropriate medicines, dose, adequate time and at the lowest cost. Irrational (inappropriate, improper, incorrect) use of medicines is when one or more of these conditions are not met. Common examples of irrational drug use are: polypharmacy, inadequate doses or duration, antibiotics prescribed for non-bacterial infections, 
prescriptions do not follow clinical guidelines, and animal owners self-medicate inappropriately or do not adhere to prescribed treatment [21]. Worldwide, it is estimated that over half of all medicines are prescribed, dispensed or sold inappropriately [15]. Irrational drug use has led to economic loss in animal industry and cause health problems in humans; it has also caused prolonged hospitalization, adverse drug reactions, treatment failures, increased cost of treatment, and reduced socio-economic status of many individuals globally. These problems are likely to increase in future unless there is an urgent instituting of control measures involving all stakeholders on the rational use of drugs globally [18].

Factors that have led sudden realization for rational drug use are: prevent drug explosion, efforts to prevent the development of resistance, growing awareness, and decreased cost of the treatment and consumer protection act. But problems like lack of information, faulty $\&$ inadequate training and education of medical graduates, poor communication between health professional and patient owner, lack of diagnostic facilities/uncertainty of diagnosis, demand from the patient and so on are causing ineffective and unsafe treatment, exacerbation or prolongation of illness, distress and harm to patient and increase the cost of treatment [4].

An excessive use of antibiotics in food-producing animals may lead to irrational. This practice favors the emergence and spread of resistant bacteria in both animal and human populations. The routine use of antimicrobials in vast numbers of healthy animals is likely to result in the emergence and spread of anti-microbial-resistant bacteria, and cause resistant infections in animals and humans. Microorganisms of food producing animals can spread to humans through consumption of contaminated food, direct contact, or by environmental spread, for example in contaminated water. As worldwide; a result of antimicrobial resistance affecting the food supply of one country becomes a potential problem for other countries [20].

The overuse and misuse of these agents leads to increased selection of resistant pathogenic bacteria that can spread among different species of animals and to humans. The consequences of these bacterial diseases are results in poor animal production, increased death of the animals leading to increased cost of production, increased emergence and spread of resistant zoonotic bacterial diseases that can affect the human population worldwide [1].

The countries that rely on agriculture as their source of income will be greatly affected due to reduced animal production, quarantine and embargo on export and imports of animal products as well as the high cost of production, many food and animal industries will be affected due to lack of raw materials and malnutrition can be a major problem since many people especially children from poor developing countries will lack animal products as nutrients [10]. Therefore the objectives of this paper were to study the irrational use of veterinary drugs in food producing animals in Adami tulu jiddokombolcha district with respective of farmers, veterinary clinicians and veterinary pharmacist. And assess the factors those leads to irrational uses of veterinary drugs in the district.

\section{Material and Methods}

\subsection{Description of the Study Area}

The study was conducted from November 2014 to March 2015 in Adami-Tulu Jiddo Kombolcha district. Geographically, Adami tulu Jiddo Kombolcha is situated in the mid-rift Valley, East showa zone of Oromia regional state, which lies at $167 \mathrm{kms}$ south of Addis Ababa. It has an altitude of 1650 meters above sea level with a bimodal unevenly distributed rainfall pattern. The average annual rain fall is $760.9 \mathrm{~mm}$ and consisted of short rainy season (February to April) and long rainy season (July to September). AdamiTulu has a minimum mean temperature of $12.7^{\circ} \mathrm{C}$ with a relative humidity of $60 \%$. Vertisol is the predominant soil type with sand-silt-clay in the proportion of $33: 48: 18$, respectively and a ph of 7.9. The livestock population of the district was estimated to be 211559 cattle, 116585 goats, 25114 sheep, 23720 donkeys, 1441 horses, 423 mules and 13059 chickens [20]. So, the predominant land around the area is suitable for livestock production and goats are being the most selected for breeding purpose next to cattle.

\subsection{Study Population}

The target study population was livestock farmers, veterinary clinicians and private veterinary pharmacists in the study area.

\subsection{Study Design and Sampling Method}

The study is predominately cross sectional. It was done on three groups those were 60 respondents (farmers) from five peasant association (Hurufa lole, Abine germama, Golba aluto, Eddo kontola and Bochessa), 10 animal health professionals (veterinary clinician) and 10 private veterinary pharmacy owners (veterinary pharmacists) from four towns (Jiddo, Bulbula, Tulu, and Batu) were selected by simple random selection or lottery method within the district. Hence, the problems they faced were identified and evaluated after they were provided with questionnaire survey format and interviewed accordingly. The study instrument was a questionnaire which contains closed and open-ended questions. The instrument was pretested, and produced in one language (English) and translated to the farmers' native language (Afaan Oromo) and the language they can more (Afaan Oromo or Amharic) for clinician and pharmacists during interviewing. The questionnaire covered the general survey characteristics such as: under farmers (farmers' basic information on the use of veterinary drugs, animal disease treatment approach, awareness on drug use and post treatment management of animals and considerable factors for irrational use of veterinary drugs); under veterinary clinician (farmers' responsibility on animal health care, casedrug issue and disease treatment options) and under veterinary pharmacists (drug sale protocol). 


\subsection{Sampling Procedure}

Three-stage sampling techniques were used to generate the required primary data. At the first stage, 1 district purposely was selected. In the second stage, randomly 5 peasant associations and 4 towns were selected from the district. Finally, a probability proportional to population size, sampling procedure was employed to select 60 farmers, 10 veterinary clinicians ( 4 government and 6 private) and 10 private veterinary pharmacists, those were respond to the questionnaires format with the totality of 80 respondents' and were included for the analysis of this qualitative information.

\subsection{Data Management and Analysis}

The collected data was entered in to Microsoft excel (Excel, 2007) spread sheet for further analysis. The data was summarized using descriptive statistics and chi square $\left(\chi^{2}\right)$ in order to assess the association between different comparable variables. A result was represented mainly by percent (\%) and frequency (n) to describe variables' characteristics. In all cases, the SPSS version 20 was used and the confidence level was held at $95 \%$ and the results were considered significant when $\mathrm{P}<0.05$.

\section{Result}

\subsection{Farmers' Response in Relation to Drug Use}

Among 60 farmers interviewed, majority of respondents 55 $(91.7 \%)$ of them uses veterinary drugs while $5(8.3 \%)$ of them do not use any veterinary drugs. Of 55 respondents $80 \%$ of them treat their animals by presenting to the clinic and $20 \%$ of them treat their animals with veterinary drugs by themselves at home, even though they have no knowledge about veterinary drugs use as shown in (Table 1).

Table 1. Farmers' response in relation to drug use.

\begin{tabular}{|c|c|c|c|c|}
\hline \multirow{3}{*}{ Parameters } & \multicolumn{4}{|l|}{ Farmers response } \\
\hline & \multicolumn{2}{|l|}{ YES } & \multicolumn{2}{|l|}{ NO } \\
\hline & no. of respondent & Percent (\%) & no. of respondent & Percent (\%) \\
\hline Do you Use vet drugs? & 55 & 91.7 & 5 & 8.3 \\
\hline Do you treat your animal by Presenting to clinic? & 44 & 80 & - & - \\
\hline Do you treat your animal by vet drugs at home? & 11 & 20 & & \\
\hline
\end{tabular}

*no. number.

\subsection{Farmers' Response in Relation to Source of Drugs They Use}

Out of 60 farmers, 18 of them use drugs from black market and almost all 17 94.4\%) of them responded as a drug from this source have no response to treatment. Of the total 60 farmers, $2236.6 \%$ ) uses veterinary pharmacy as a drug source and $29.1 \%$ ) of them responded as this source of drugs have no response to treatment and $2033.6 \%$ ) uses veterinary clinic as a drug source and $3(15 \%)$ of them responded as this source of drugs have no response to treatment. So, there was statistically a significance difference $(\mathrm{P}<0.05)$ between source of drug and response of animals to treatment as presented in the (Table 2).

Table 2. Farmers' response in relation to source of drugs they use and response to $R_{x}$ of $D^{+}$.

\begin{tabular}{|c|c|c|c|c|c|c|c|c|}
\hline \multirow{3}{*}{ Source of drugs } & \multicolumn{6}{|c|}{ Response to $\mathrm{D}^{+} \mathbf{R}_{\mathrm{x}}$} & \multirow{3}{*}{$\chi^{2}$} & \multirow{3}{*}{ P-value } \\
\hline & \multicolumn{2}{|c|}{ YES } & \multicolumn{4}{|c|}{ NO } & & \\
\hline & no & Percent (\%) & no & Percent (\%) & Total & Percent (\%) & & \\
\hline Vet. Pharmacy & 20 & 90.9 & 2 & 9.1 & 22 & 36.7 & & \\
\hline Black market & 1 & 5.6 & 17 & 94.4 & 18 & 30 & 37.123 & .000 \\
\hline Vet clinic & 17 & 85 & 3 & 15 & 20 & 33.3 & & \\
\hline Total & 38 & 63.3 & 22 & 36.7 & 60 & 100 & & \\
\hline
\end{tabular}

$*$ no. Number, $* \mathrm{R}_{\mathrm{x}}$. Treatment, $* \mathrm{D}^{+}$. Disease.

\subsection{Farmers' Response on Drug Regulation Problems}

Majority of respondents $42(70 \%)$ out of 60 responded as there were; drug supply problems and lack of vet supervision while, $44(73.3 \%)$ of them responded as there were lack of access of vet professions which leads to irrational use of veterinary drugs in study area (Table 3 ).

Table 3. Farmers' response on drug regulation problem.

\begin{tabular}{|c|c|c|c|c|}
\hline \multirow{3}{*}{ Parameter } & \multicolumn{4}{|c|}{ Farmers response } \\
\hline & \multicolumn{2}{|l|}{ YES } & \multicolumn{2}{|l|}{ NO } \\
\hline & Frequency (n) & Percent (\%) & Frequency (n) & Percent (\%) \\
\hline Is there drug supply problem? & 42 & 70 & 18 & 30 \\
\hline Is there lack of vet supervision? & 42 & 70 & 18 & 30 \\
\hline Is there lack access of vet professions? & 44 & 73.3 & 16 & 26.7 \\
\hline
\end{tabular}




\subsection{Farmers' Side Problem on Irrational Use of Veterinary Drugs as Veterinarian Responses}

Out of the total 10 clinician interviewed, $2(20 \%)$ of clinicians responded as the farmers do not accept their advice on animal treatment and $1(10 \%)$ of clinician depends on the farmers need due to factors like distance from the clinic and business which leads for irrational use of veterinary drugs as shown in the (Table 4).

Table 4. Farmers' side problem on irrational use of drugs as clinician response.

\begin{tabular}{|c|c|c|c|c|}
\hline \multirow{3}{*}{ Parameter } & \multicolumn{4}{|c|}{ Clinician response } \\
\hline & \multicolumn{2}{|c|}{ YES } & \multicolumn{2}{|l|}{ NO } \\
\hline & Frequency (n) & Percent (\%) & Frequency (n) & Percent (\%) \\
\hline Do farmers accept advice? & 8 & 80 & 2 & 20 \\
\hline Does Vet depend on farmers need? & 1 & 10 & 9 & 90 \\
\hline
\end{tabular}

\subsection{Resource Related Issue for Irrational Use of Veterinary Drugs as Veterinarian Response}

From the total of 10 clinicians interviewed, $80 \%$ of them responded as there was no sufficient drug availability and also $80 \%$ of them responded as there was no effective drug for the specific disease. Of these clinicians, $90 \%$ of them treat the animals without doing any laboratory test and none of them do not do drug sensitivity test to evaluate the efficacy of the drugs. $20 \%$ of these clinicians also faced incurability of the drugs they use for some disease as presented in the (Table 5).

Table 5. Drug availability and its effectivity related issue for irrational use as clinicians' response.

\begin{tabular}{|c|c|c|c|c|}
\hline \multirow{3}{*}{ Parameters } & \multicolumn{4}{|l|}{ clinical response } \\
\hline & \multicolumn{2}{|l|}{ YES } & \multicolumn{2}{|l|}{ NO } \\
\hline & Frequency (n) & Percent (\%) & Frequency (n) & Percent (\%) \\
\hline Does drug available as needed? & 2 & 20 & 8 & 80 \\
\hline Are there effective drugs for cases? & 2 & 20 & 8 & 80 \\
\hline Do you do lab? & 1 & 10 & 9 & 90 \\
\hline Do you do drug sensitivity test? & 0 & 0 & 10 & 100 \\
\hline Have you faced drug incurability? & 2 & 20 & 8 & 80 \\
\hline
\end{tabular}

\subsection{Response of Pharmacists on Issues Related to Irrational Use of Veterinary Drugs}

Of the total 10 veterinary pharmacists $7(70 \%)$ of them sell drug to anybody and also $70 \%$ of them sell the drug without prescription as well as most $(80 \%)$ of them do not depend on the history of the disease. Each of these parameters are anticipated as some of the reasons contributing the irrational use of veterinary drugs in study area as indicated in (Table 6).

Table 6. Pharmacists' response on issue related to drug irrational use.

\begin{tabular}{|c|c|c|c|c|}
\hline \multirow{3}{*}{ Parameter } & \multicolumn{4}{|c|}{ pharmacists' response } \\
\hline & \multicolumn{2}{|c|}{ YES } & \multicolumn{2}{|l|}{ NO } \\
\hline & frequency & percent & frequency & percent \\
\hline Do you Sell drug without prescription? & 7 & 70 & 3 & 30 \\
\hline Do you Sell by prescription? & 3 & 30 & 7 & 70 \\
\hline Do you Sell by history of $\mathrm{D}^{+}$? & 2 & 20 & 8 & 80 \\
\hline
\end{tabular}

$*_{\mathrm{D}}^{+}$. Disease.

\section{Discussion}

Drug access is a combination of three factors: availability, affordability and rational use. In developing countries, drugs of standard quality are not available; the majority of the population cannot afford the high cost of the available drug therapies; and drugs are not rationally used [12]. In biomedical context the following criteria may be used to qualify an act as rational use of drugs [9]; appropriate indication, appropriate drug, appropriate dosage, appropriate patient, correct dispensing and patient adherence to the treatment.

In the current study a total of 80 respondents of wich 60 farmers, 10 veterinary clinicians and 10 veterinary pharmacists were interviewed to evaluate the irrational use of veterinary drugs by collecting information as a questionnaire survey. The study showed that out of 60 farmers, 55 (91.7\%) of them uses veterinary drugs in different ways. Among these, $44(80 \%)$ of them treat their animals by presenting to the clinic and $11(20 \%)$ of them treat their animals with veterinary drugs by themselves at home, even though they have no knowledge about veterinary drugs use. The farmers those treat their animals by themselves at home might be due to distance or absence of veterinary clinic in the area and lack of awareness about the effect of drug when used incorrectly. On the other hand, treating animals by themselves in various communities in most countries is a problem where individuals use drugs or pharmaceutical products like 
antibiotics, to treat by themselves with drugs prescribed by the animal health professionals for a chronic or recurring diseases cause an irrational use of drugs [22].

There was statistically significant association between source of drugs and effectivity of drugs $(\mathrm{P}<0.05)$. Of the total 60 farmers, 18 (30\%) uses black market, 22 (36.7\%) uses veterinary pharmacy and $20(33.3 \%)$ uses veterinary clinic as a source of drugs. Among these 17 (94.4\%), 2 (9.1\%) and 3 $(15 \%)$ of them responded as these sources of drugs have no response to treatment from the black market, veterinary pharmacy and veterinary clinic respectively. Each of these three sources of veterinary drugs plays an important role in an irrational use of drugs. In the district, black-market drug dealers were found to be challengers of private practitioner, veterinary service and even government veterinary service. These is because of high price of animal drugs in veterinary clinic and veterinary pharmacy, most farmers have been compelled to devise strategies for survival of their livestock enterprises. Such measures include buying cheaper drugs, reducing treatment interval or reducing the dosage of drug administered to animals. Likewise, the ability of the drugs bought from the black market was very much low in curing animal diseases in relative to the other two sources mentioned in the (Table 2). For instance, a drug bought from black market might be expired and low quality due to improper storage site and farmers used these without indication, inappropriate dosage and route of administration. This was the side effect of using drugs illegally which has public and economic importance in the study district. In study area one of the factors that promote use of blackmarket drugs was its low price compared to other source.

Black-market dealers are circulating low quality drugs, and this was found to be cause for exacerbated administration of drugs by untrained farmers and faced no response on treatment of disease. This situation possibly caused lowering of the demands of veterinary service in the area and can be the main reason for the occurrence of drug residue and emergency of drug resistant microorganisms [7], since majority of users are illiterate and have no knowledge of drug expiration and withdrawal period. Therefore, availability of these contraband veterinary drugs accompanied by the farmers themselves treating their own sick animals is resulted in drug misuses, drug abuse and losses of animals. On the other hand drugs bought from veterinary pharmacy and veterinary clinics by the farmers might be unable to cure the disease in small instance due to the factors like with disease diagnosis, incorrect dose and time of drug administration.

On the other ways majority of respondents $42(70 \%)$ out of 60 responded as there were; drug supply problems and lack of vet supervision while, $44(73.3 \%)$ of them responded as there were lack of access of veterinary professions in study area as shown in (Table 3). As the result, lack of sustainable drug supply source with reasonable price, absence of supervisions and lack of access of veterinary professionals were identified as causes of weakening of veterinary services and leads to irrational use of drugs [19]. This can be due to existing lacks of operational budget and logistic problem of veterinary offices and lack of access of veterinary professionals are other bottlenecks for supervision activities to be carried out.

In line with clinicians, Out of the total 10 interviewed, 2 (20\%) of clinicians responded as the farmers do not accept their advice on animal treatment and $1(10 \%)$ of clinician depends on the farmers need. This might be due to factors like distance from the clinic, lack of awareness on effects of drug irrational use and also availability of traditional medication in an area.

On other side, as the result indicate from (Table 5), of the total 10 clinicians interviewed, $8(80 \%)$ of them responded as there was no sufficient drug availability and also $8(80 \%)$ of them responded as there was no effective drug for the specific disease. Of these clinicians, $9(90 \%)$ of them treat the animals without doing any laboratory test and none of them do drug sensitivity test to evaluate the efficacy of the drugs. $2(20 \%)$ of these clinicians also faced incurability of the drugs they use for some disease. This might be due to inadequate budget, lack of basic veterinary equipments, shortage of trained manpower and low capacity of veterinary section were found to be main causes for the weakness of conventional veterinary. In addition to this, almost all veterinary clinics are suffering with lack of basic laboratory equipments and kits to diagnose specific cases visiting clinics and faced drug incurability upon treatment of disease in study area.

As the study showed from response of pharmacists, 7 $(70 \%)$ of them sell drug to anybody without prescription as well most, $8(80 \%)$ of them do not depend on the history of the disease. Each of these parameters are anticipated as some of the reasons contributing the irrational use of veterinary drugs in study area as indicated in table 6 . This could be due to the fact that majority of pharmacists particularly private pharmacists consider about their business rather than farmers benefit. Majority of private pharmacists distributes low quality drugs to deworming drugs for internal parasite used without prescription [80] which is only for the seek of their business rather than animal health and community benefit.

\section{Conclusion and Recommendations}

The overall result observed in the study indicates there were an important ways of drug irrationally used in the area and this could be due to several factors of which farmers and animals health professionals acts by themselves. Generally irrational use of veterinary drugs is a common problem globally especially in developing countries where resource and educated human power are not access as wanted. For the most, presence of black market dealers, illiterate farmers, insufficient access of animals' health care sectors and veterinary equipments are among the major factors that enforce community and animal health professionals as to use veterinary drugs irrationally in the study area.

Based on the result obtained in the present study and considering the reality in the district, the following relevant points are recommended to alleviate the expansion of 
veterinary drugs use irrationally and reduce its economic impact, public health impacts as well.

Controlling the availability of veterinary drugs contraband with the black market dealers.

The government should training large number of students on veterinary profession and upgrading existing animal health technician to solve shortage of trained manpower and fulfilling veterinary material in such remote area.

Growing awareness in the community and health professionals about rational use of veterinary drugs and its impact on economic and human health when used irrationally.

\section{Acknowledgements}

The researcher group would like to thank Jimma university for valuable financial and advisory contribution.

Again our gratitude thanks extend to Adami Tulu Jiddo Kombolcha fishery and livestock development office for facilitation of our work.

\section{References}

[1] Amin, N. (2011). Use and misuse of antibiotics. Ibrahim Cardiac Medical Journal. 1 (2): 7-9.

[2] ATJK. (2008). Adami Tulu Jido Kombolcha distrct Live stock Development and Health bureau. Brahm, D., Marak, M., Wahalang, J. (2012). Rational use of drugs and irrational combinations. Internet. J. pharmacol. 10 (1).

[3] FAO/OIE/WHO. (2003). Expert workshop on non-human antimicrobial resistance: scientific assessment. Geneva, Switzerland. Pp. 19-20.

[4] Giguere, S. (2006). Antimicrobial Drug Action and Interaction: An Introduction. Antimicrobial therapy in Veterinary Medicine 4th edn, S Giguere, JF Prescott, JD Baggot, RD Walker and PM D owling, eds. Blackwell Publishing, Ames Iowa, USA.

[5] Hirsh, D. C., Zee. (1999). Veterinary microbiology, 1st ed. Blackwell publishing Company, California. Pp. 48-57.

[6] Kanneene, J. B., Miller, R. (1997). Problems associated with drug residues ion beef form feeds and therapy. Rev. Sci. Technol. 16: 694-708.

[7] Kardas, P., Devine, S., Golembesky, A. and Roberts, C. (2005) A systematic review and meta-analysis of misuse of antibiotic therapies in the community. International Journal of Antimicrobial Agents, 26, 106-113.

[8] Kumbe, A., Hilo, A., Begna, F. and Hussien B (2020) Prevalence and associated risk factors of fasciolosis and paraphistomosis in sheep in and around Batu town. J Vet Med Res 7 (1): 1181.

[9] Le Grand A. (1999). Interventional Research in Rational Use of Drugs: A Review. Health Policy and Planning, 14 (2): 89102.

[10] Planta, M. B. (2007). The Role of Poverty in Antimicrobial Resistance Journal of the American Board of Family Medicine. 20 (6): Pp. 533-539.

[11] Prescott, J. F., Baggot, J. D. (1993). Antimicrobial therapy in veterinary medicine, 2nd ed. Low state university press. Amsterdam. Pp. 564-565.

[12] Vazquez, E. C. S. (2003). Increasing Drug Access for the Poor Using Generic Drugs: Regulation and Policy Alternatives Pp. 108-112.

[13] WHO (2000). World Health Organization Global principles for the containment of antimicrobial resistance in animals intended for food. Report of WHO consultation with the participation of the FAO and OIE in Switzerland, Geneva.

[14] WHO (2001). Monitoring antimicrobial usage in food animals for the protection of human health, reports of a WHO Consultation, Oslo, Norway.

[15] WHO (2002). WHO policy perspectives on medicine promoting rational use of medicine. Available from: WHO model formulary. Geneva: WHO Press.

[16] WHO (2004). World Health Organization Model Formulary, WHO press, Geneva, Switzerland.

[17] WHO (2006). The role of education in the rational use of medicines. SEARO Technical Publication Series No. 45, World Health Organization, Regional Office for South- East Asia, New Delhi, Pp 1-101.

[18] WHO (2007). Progress in the rational use of medicine s. World Health Assembly Resolution. Document No. WHA60.16. World Health Organization, Geneva: WHO, Pp. 71.

[19] WHO (2010). Rational use of medicines. World Health Organization (WHO)/rational use of Medicines. http://wwwwhoint/medicines/areas/rational_use/en/.

[20] WHO (2011). World health day 2011.

[21] WHO. (2012). Rational use medicines Accessed on 03 November 2013 from: http:/www, who, $\mathrm{int} /$ medicines/areas/rational use/en/index html.

[22] Widayati, A., Suryawati, S., Decrespigny, C. and Hiller, J. E. (2011). Self medication with antibiotics in Yogyakarta City Indonesia: A cross sectional population-based survey. BMC Research Notes, 491. http://dx.doi.org/10.1186/1756-0500-4-491. 